folk/ed. Derg, 2020; 26(4):985-1002

DOI: $10.22559 /$ folklor.1312

\title{
Kadim Süryani Atasözlerinin Kaynağı ve Rolü (Mardin Örneği)
}

\author{
Source and Role of Khadim Syriac Proverbs \\ (Example of Mardin)
}

\section{Halit Yeşilmen ${ }^{*}$}

\section{Öz}

Makalenin konusu, Süryani atasözleridir. Süryaniler, kullandıkları atasözlerinin kaynağı olarak genellikle Kutsal Kitap'1 ve Süryani Büyükleri'nin özdeyişlerini işaret ederler. Kutsal Kitap’ta yer alan sözler, sosyal alana aktarılırken zamanla atasözü formunun oluşmasına kaynaklık etmektedir. Bu durum, özdeyişler için de geçerlidir. Bu açıdan makalede Süryani atasözlerinin kaynağı ve rolü sorgulanmıştır. Bu sorgulama için Mardin ilinden on beş Kadim Süryani ile görüşülmüş ve onlardan atasözleri derlenmiştir. Bununla birlikte, Kutsal Kitap'tan ve özdeyişlerden örnek sözlere de yer verilmiştir. Amaç hem saha çalışmasıyla Süryani atasözlerini tespit etmek ve bunların değerlendirilmesinde genel bir çerçeve belirlemek hem de atasözlerinin Süryaniler açısından oynadığı temel rolü ortaya koymak olmuştur. Süryani atasözlerinin üç temel kaynağı olduğu sonucuna ulaşılmıştır: biri Kutsal Kitap’tır; ikincisi, Kutsal Kitap merkezinde şekillenen Süryani Büyükleri’nin özdeyişleridir; üçüncüsü ise sosyo-kültürel dinamiklerdir. Süryani atasözlerinde iki temel belirleyici yön ve rol saptanmıştır. Birincisi Kutsal Kitap merkezinde öğütlenen erdemli yaşamın aktarılmasına aracılık eden atasözleri, diğeri ise bundan bağımsız bir şekilde, 
daha çok sosyo-kültürel dinamiklerin ve sosyo-kültürel okuma biçimlerinin belirlediği ve bunların aktarılmasına aracılık eden atasözleridir. Sosyo-kültürel dinamiklere bağlı olarak bu iki rolün zayıfladığı görülmüştür. Genel olarak bu çalışma, derleme yoluyla yeni veriler oluşturarak hem kültürel dinamikleri hem de Süryani kültürünü anlamaya ve yorumlamaya katkı sunmayı hedeflemiştir.

Anahtar sözcükler: kültür, sözlü kültür, kadim Süryaniler, atasözleri, özdeyişler, Mardin

\begin{abstract}
This paper investigated Syriac proverbs as they often point out the Bible and aphorisms as their source. While the words in the Bible are transferred to the social field through aphorisms, they also cause the formation of the proverbial form over time. This is also prevalent to aphorisms. In this context, the source and role of Syriac proverbs has been investigated in this study. To this aim, fifteen Khadim Syriacs from Mardin have been interviewed and proverbs have been compiled based on their responses. In addition, sample words from the Bible and the aphorisms have been included in the data collection. The aim was to both compile the Syriac proverbs with the field study and to determine a general framework for their evaluation, and reveal the main role of the proverbs for the Syriacs. The results showed that the Syriac proverbs have three main sources. The first source is the Bible; secondly, the aphorisms that Syriacs consider important; and thirdly, the socio-cultural dynamics that are effective in interactions with different groups or within the same group. Within this framework, two basic aspects and roles were identified in Syriac proverbs. The first is the proverbs, which mediate the transfer of life of wisdom that the Bible advises; and the other one is the proverbs, which are determined by socio-cultural dynamics and mediate the transfer of socio-cultural reading ways independently. It has been observed that these two roles decreased due to socio-cultural dynamics. This study hopes to contribute to the understanding and interpretation of the culture of Syriac by creating new data.
\end{abstract}

Keywords: culture, orality culture, khadim Syriacs, proverbs, aphorisms, Mardin

\title{
Extended summary
}

The proverbs that have been formed over many years with the interpretation, description and narration of various events are one of the important means of transmission of sociocultural dynamics and collective memory. Besides proverbs reflect a group's method of reading, interpreting and describing events. The use of proverbs in daily life, which can be considered as one of the first forms of speech; It almost disappears with factors such as modernization, globalization and digital technology. This situation is also prevalent in Syriac proverbs. In this context, the subject of this article is about Syriac proverbs. 
Syriacs are an ethno-religious group that has oral culture elements in terms of both religious resources and socio-cultural life. While the words in the Bible are transferred to the social field through aphorisms, they also cause the formation of the proverbial form over time. This is also eligible for the aphorisms of Syriac ancestors. Therefore, Khadim Syriacs generally points out the Bible and aphorisms as the source of their proverbs. This approach causes the "Syriac Proverbs" literature to remain empty, or undersized, in research on Syriacs. However independently of these, there are also proverbs stemming from sociocultural dynamics, and these are considerable. In this context, the source and role of Syriac proverbs has questioned in the article. A field study has made for this questioning. In this field study, fifteen Khadim Syriacs from Mardin and Syriac villages have interviewed and proverbs have been compiled from them. In addition, the study titled "Syriac Proverbs" written by Ercan Akçay, and "Ordspråk \& Aforismer" written by Gabriel Afram have been included in the questioning for the detection of Syriac proverbs. Moreover, exemplary words from the Bible and the aphorisms of Syriac ancestors have been included.

The aim of the study is to compile both the Syriac proverbs with the field study and to determine a general framework for their evaluation, and to reveal the main role of the proverbs for the Syriacs. For this purpose, along with the proverbial examples in the Bible, the expressions of "Ahikar" and Mor Efrem, one of the Syriac ancestors, have also included. Additionally, examples of proverbs derived from them have been given. Finally, the Syriac proverbs, which might be qualified independently from these and compiled from the field, have been introduced.

In this article, proverbs have been dealt with in various main themes. These themes are divided in to eight categories as follows: 1) wisdom; 2) decency, correctness and beneficence/ kindness; 3) kinship, friendship and solidarity; 4) to work, to diligence and provide livelihood; 5) ideal attitudes towards economic gain; 6) being cautious; 7) overcoming distressed situations, and in addition; 8) proverbs about some social issues and their solutions. Apart from these, proverbs describing various events and situations encountered in socio-cultural life have also included.

As a result, it has been seen that the Syriac proverbs have three main sources. Firstly, it is the Bible. Secondly, they are the aphorisms that Syriacs consider important. Thirdly, they are socio-cultural dynamics that are effective in interactions with different groups or within group. It has been concluded that words stemming from the Bible and the aphorisms of Syriac ancestors, which are shaped in the center of the Bible, have an active role in the explanation and interpretation of social life. Proverbs of this kind have preserved and transport this effect. Proverbs, which are independent of these, have also identified. It has been identified that these proverbs reflect the socio-cultural experiences and specific reading styles of the Syriacs. It has observed that proverbs differed within the determined categories, and the difference was more evident especially in the 5th, 6th, 7th and 8th categories. In this framework, two basic aspects and role have been identified in Syriac proverbs. The first is the proverbs, which mediate the transfer of life of wisdom that the Bible advises, the other one is the proverbs, which are determined by socio-cultural dynamics and mediate the transfer 
of socio-cultural reading ways independently. It has observed that these two roles decreased due to socio-cultural dynamics.

Main reasons such as the modern process and population decline (migration) have been reduced the use of proverbs in social life. At the same time, these causes have also weakened the dynamics of wisdom and use of proverbs that mediated the transfer of wisdom. There is a greater need for field research in Syriac culture. At this point, it could be said that the Syriac culture is worth a treasure. In this context, one of the signifigance of this article has been to comprehend and interpret the Syriac culture by creating new data through compilation.

\section{Giriş}

Atasözlerinin gündelik yaşamdaki kullanımı modernleşme süreci ile birlikte her geçen gün azalmaktadır. Modernleşme sürecinde gelenek olarak tanımlanan sosyo-kültürel yapılar zayıflarken küreselleşme ve dijitalleşme sürecinde ise sözlü iletişimin varlığg tehdit altındadır. $\mathrm{Bu}$ yönüyle atasözleri, çeşitli sorgulamalara konu olabilecek değerdedir. Nihayetinde “atasözleri” (1), sözlü kültürün ve sözlü iletişimin (2), kısacası yüz yüze etkileşimin vazgeçilmez bir yönüdür. Kültürün değersel değişimi eşliğinde kolektif hafizanın önemli aktarım araçlarındandır. Atasözleri; halk edebiyatı, halk bilimi, folklor gibi sosyal disiplinler başta olmak üzere sosyal antropolojinin de ilgi alanlarındandır. Halk edebiyatı ve folklorda; gramatik özellikler, anlam ve edebi değerler gibi kategorilerle doğrudan konu edilmektedir. Anlam açısından inanç, ögüt ve ahlaki ilkeleri içeren, ayrıca sosyal deneyimler yoluyla mantıki çözümlemeler sunan, sosyal olayları ve kültürel imgeleri yansıtan mecaz nitelikleriyle ön plandadır (Kaya, 2007: 111-114). Sosyal Antropoloji disiplininde ise insana özgü ilk sözlü türlerinden biri olarak görülmekte (Ong, 2003: 21; Goody, 2017: 59), sözlü kültür bağlamında da grup üyelerinin ortak duygularının (kimliklerinin) oluşması ve aktarılmasındaki rolleriyle önemsenmektedir (Sanders, 1999: 28; Assmann, 2001: 141; Ong, 51). Bu rol, sosyo-kültürel dinamiklerin, kolektif hafizanın, ortak duyguların, olayları yorumlama biçiminin ve eylem belirleme tarzının korunmasını ve aktarılmasını da imler. Dolayısıyla kültürel ve etno-dini bir grupta atasözlerinin varlığından bahsedebilmek o grubun köklü tarihine dayalı özgül dinamiklerin varlığından, yaşam tecrübelerinden, kültürel anlam kodlarından ve birikiminden bahsetmekle eş değerdir. Özellikle Süryaniler gibi kültürel ve dini gelenekleriyle ön planda olan etno-dini bir grup söz konusu ise atasözlerinin varlığı da kaçınılmazdır.

Gelenekleriyle ve kadim bir topluluk olmakla ön planda olan Süryaniler hem Kutsal Kitap’taki (Tevrat, Zebur, İncil) sözlü kültür öğelerini (mesela; sözün kutsallı̆̆ı, özdeyiş geleneği, sezgi, mevhibe, erdem) örnek almaları hem de zanaat, ticaret, tarım gibi ekonomik yaşamları bakımından sözlü kültür unsurlarına sahiptir. Dolayısıyla Süryanilerdeki sözlü kültür dinamiklerinin ve bu kapsamda atasözü literatürünün araştırılması gerekir. Bu çerçevede makalenin konusu, Süryani atasözleridir: Süryani atasözlerinin rolü ve bu rolü belirleyen, onların oluşmasına kaynaklık eden unsurlar sorgulanmaktadır. Süryaniler, kullandıkları atasözleri için genellikle Kutsal Kitap’taki sözleri ve Süryani Büyükleri'nin özdeyişlerini kaynak olarak gösterirler. Bu da ilgili araştırmalarda "Süryani Atasözleri” literatürünün zayıf 
kalmasına sebep olmaktadır. Bu durum göz önünde bulundurularak Mardin'deki "Kadim Süryani (Süryani Kadim) Cemaati” ile sınırlandırılmış bir alan araştırması yapılmıştır (3). 2017-2019 yılları arasında, farklı zaman aralıklarıyla yapılan bu araştırmada; Mardin merkez, merkeze bağlı Bülbül köyü, Midyat ilçesi, Midyat'a bağlı Anıtlı ve Alagöz köyünden toplam on beş Kadim Süryani ile görüşülmüş ve onlardan atasözleri derlenmiştir (4). Ayrıca Ercan Akçay’ın (2005) “Süryani Atasözleri” adlı çalışması ve Gabriel Afram’ın (2010) “Ordspråk \& Aforismer" (Atasözleri ve Özdeyişler) isimli eseri, kullanılan Süryani atasözlerinin tespiti için somut bir önemde görülerek alandaki sorgulamaya dâhil edilmiştir. Çalışmanın birincil amac1, Kutsal Kitap’tan bağımsız, sosyo-kültürel dinamiklerin bir göstergesi niteliğinde olan Süryani atasözlerini alandan tespit etmek, diğer amacı ise beslendiği kaynakları göz önüne alarak bunların temel rollerini belirlemek ve buna bağlı olarak Süryani atasözlerinin değerlendirilmesinde genel bir çerçeve çizmek olmuştur. Konunun ele alınmasında öncelikle Kutsal Kitap’ta yer alan atasözü niteliğindeki örnekler ile “Ahikar'ın Öğütleri”nde (5) ve Süryani Büyükleri'nden Mor Efrem'in (d. 285 - ö. 373) şiirlerinde yer alan atasözü niteliğindeki ifadelere ve mahiyet açısından bunlarla ortak içeriği vurgulayan, bunların türevi niteliğindeki atasözlerine yer verilmiştir. Daha sonra bunlardan bağımsız olan Süryani atasözleri ortaya konmuştur.

Süryani atasözlerinin araştırılması; genel anlamda kültürel süreçlerin, özel olarak da Süryani kültürünün anlaşılmasına ve yorumlanmasına katkı sunacaktır. Ek olarak; bir atasözünün oluşmasını sağlayan olay ve kültürel örüntüler ile atasözünün olay ve örüntüleri formüle etme ve aktarma etkisi dikkate alındığında, atasözleri ile ilgili araştırmaların sosyal antropoloji, sosyoloji ve psikoloji gibi disiplinlerde daha geniş ele alınması gerektiği de belirtilmelidir.

\section{Süryani atasözleri: Bilgeliğin ve erdemli/sağduyulu bir yaşamın sosyal hayata aktarılması}

Kutsal Kitap'ta bilgelik/hikmet merkezinde farklı isimlere ve farklı dönemlere atfedilen özdeyişler yer almaktadır. Bu özdeyişlerde bilgece ve sağduyuya dayalı erdemli bir yaşam öğütlenmekte, sosyal yaşamdaki sorumluluklara dikkat çekilmektedir. Bilgelik yolunda terbiyeye ulaşmak, söz ve eylemde doğru olmak, adaleti gözetmek, şerli ayartmalara kanmadan bilgece yaşam sürmek ve bu yönde tedbirli olmak gibi ögütleri içeren özdeyişler (Bk. Kutsal Kitap, 2009: Özd. 1/1-6), içerikleri ve vurgulamaları bakımından gündelik yaşamda atasözü formunda kullanılabilecek bir niteliğe de sahiptir. Bu nitelikteki ifadeler ve Süryani Büyükleri'nin özdeyişleri, zamanla kaynağından bağımsız bir şekilde Süryani atasözlerinin oluşmasını da etkilemiştir. Farklı sebepleri olmakla birlikte Süryanilerin, günümüzde kullandıkları atasözleri için bu iki kaynağa işaret etmeleri, belirtilen süreçle ilişkilidir. Nihayetinde Kutsal Kitap, özdeyiş ve sözlerin derlenmesini dışlamadığı gibi atalardan intikal eden bilge sözlere sahip çıkılması gerektiğini de belirtmekte ve bunun örneklerini sunmaktadır (Bk. Mez. 78/1-4; Vai. 12/9-13). Bunlardan farklı olarak sosyokültürel yap1 ve dinamiklerden kaynaklanan Süryani atasözleri de söz konusudur. Sosyal 
dinamiklerden kaynaklanan atasözlerine yer vermeden önce genel bir çerçevenin belirlenmesi için ilk önce Kutsal Kitap'tan ve Süryani Büyükleri’nin özdeyişlerinden bazı örneklere yer vermek gerekir. Bu örneklerle hem atasözü formundaki ifadeler ortaya konmakta hem de sözlerin, belirli bir temanın aktarılmasına aracılık ettiği hususu takip edilmektedir.

\subsection{Kutsal Kitap'ta atasözü niteliği taşıyan bazı sözler}

Kültür gibi kutsal metinler de kendi bağlamı içerisinde anlam sunarlar. Dolayısıyla bir cümlenin bağlamından soyutlanması, karşıt bir anlam riskini de beraberinde getirebilir. $\mathrm{Bu}$ risk dâhilinde aşağıda, anlam içeriğinden hareketle belirlenen ana kategoriler içerisinde Kutsal Kitap'tan derlenen örnek sözlere yer verilmektedir. Ana kategoriler, diğer atasözleri çeşitlerinde de kullanılmaktadır ki böylece söz konusu edilen yön/kaynak farkına (bilgelik ile sosyo-kültürel dinamikler) belirlilik kazandırılmaktadır.

\section{a. Kutsal Kitap’ta doğrudan bilgelik ile ilgili olan bazı sözler}

“Bilgeliğin (hikmetin) başı, Rab korkusudur.” (Mez. 11/10).

"Bilgelik, güçten iyidir." (Vai. 9/16).

“Kişi sağduyusu oranında övülür.” (Özd. 12/8).

“Bilgenin azarını işitmek, akılsızın türküsünü işitmekten iyidir.” (Vai. 7/5).

"Söz çoğaldıkça anlam azalır." (Vai. 6/11).

“İnsan, ne ekerse onu biçer.” (Gal. 6/7).

“Erdemli kadın, kocasının tacıdır.” (Özd. 12/4).

Çalışmada atasözü formuna dikkat çekildiği için bilgelik ile ilgili bir kaç örneğe yer verildi. Kutsal Kitap’ta bilgelik, sunulan özdeyişlerin ana teması ve gündelik yaşamdaki erdemli davranışların da temel kaynağı olarak belirtilir. Bilgelik yolunda özdeyişler derlemek, bilgelerin öğütlerini dinlemek, erdem ve sağduyu sahibi olmak da bilgeliğin gerekliliği olarak zikredilir (Bk. Özd. ; Vai. 12: 9-13; Mez. 78: 1-4). Bu açıdan Kutsal Kitap’tan verilen örneklerin bilgelik çerçevesinde yer aldığı belirtilmelidir.

\section{b. Kutsal Kitap'ta terbiye/eğitim, doğruluk ve iyilik ile ilgili bazı sözler}

“Akılsız çocuk, babasının başına beladır.” (Özd. 19/13).

“Dikenli bitkilerden üzüm, deve dikenlerinden incir toplanabilir mi?” (Mt. 7/16).

“Kardeşinin gözündeki çöpü görürsün de kendi gözündeki merteği fark etmezsin.” (Lu. 6/41).

“İyi ağaç, iyi meyve verir; kötü ağaç, kötü meyve verir.” (Mt. 7/17).

“İyi ad, hoş kokulu/lezzetli yağdan değerlidir.” (Vai. 7/1).

\section{c. Kutsal Kitap'ta yakınlık, dostluk ve yardımlaşma ile ilgili bazı sözler}

"Yakın komşun, uzaktaki kardeşten iyidir." (Özd. 27/10).

“İki kişi, bir kişiden iyidir.” (Vai.4/9). 
“Demir demiri biler, insan da insanı.”(Özd. 27/17).

"Vermek, almaktan daha büyük bir mutluluktur." (Elç. 20/35).

\section{d. Kutsal Kitap'ta çalışmak ve geçimini sağlamak ile ilgili bazı sözler}

“Gevşemezsek mevsiminde biçeriz.” (Gal. 6/9).

“Çalışmak istemeyen yemek de yemesin.” (2Se. 3/10).

“Sağ köpek, ölü aslandan iyidir.” (Vai. 9/4).

“Borç alan, borç verenin kulu olur.” (Özd. 22/7).

“Öküz yoksa yemlik boş kalır.” (Özd. 14/4).

“Tembel der ki: Dışarıda aslan var, sokağa çıksam beni parçalar.” (Özd. 22/13).

“Tembellikten dam çöker, miskinlikten çatı akar.” (Vai.10/18).

\section{e. Kutsal Kitap'ta ekonomik kazanç/tutum ile ilgili bazı sözler}

“Mal çoğaldıkça yiyeni de çoğalır.” (Vai. 5/11).

“Zenginin malı, zengini uyutmaz." (Vai.1/8).

"Yarının kaygısı yarının olsun.” (Mt. 6/34).

“Devenin iğne deliğinden geçmesi, zenginin Tanrı Egemenliği'ne girmesinden daha kolaydır." (Mt. 19/24; Mar. 10/25).

\section{f. Kutsal Kitap'ta tedbirli/temkinli olmak ile ilgili bazı sözler}

“Geç öfkelenen, akıllıdır.” (Özd. 14/29).

“İlkin dışarıda işini bitirip tarlanı hazırla, ondan sonra evini yap.” (Özd. 24/27).

“Çok tasa, kötü düş; çok söz, akılsızlık doğurur.” (Vai. 5/3).

“Başkasına pusu kuran, kendi kurduğu pusuya düşer.”(Özd. 1/18).

\section{g. Kutsal Kitap'ta sıkıntılı hallere dair bazı sözler}

“Ahmağın yolu, kendi gözünde doğrudur.” (Özd. 12/15).

“Göz görmekle doymuyor, kulak işitmekle dolmuyor.” (Vai. 1/8).

“Gözün gördüğü, gönlün çektiğinden iyidir.” (Vai. 6/9).

“İçin için yanmaktansa evlenmek daha iyidir." (1Ko. 7/9).

“Taş çıkaran, taştan incinir." (Vai. 10/9).

“Eğri olan doğrultulamaz, eksik olan sayılamaz.” (Vai. 1/15).

Kutsal Kitap, atasözü formunda çeşitli öğütler/sözler içermektedir. Nitekim Kutsal Kitap’taki özdeyişlerin temel amacı, belirtilen kategorilerin içeriğiyle doğrudan ilişkili bir şekilde; bilgeliğe ve terbiyeye ulaşmak, haklı ve adil olanı yapmak, ihtiyatlı ve sağduyulu davranmak, böylece yaşam hüneri kazanmak olarak ifade edilir (Bk. Özd. 1/1-6). Söz konusu edilen ifadeler de bilgece yaşam için gerekli öğütlerin aktarılmasına aracılık ederler. Benzer bir durum, Süryani Büyükleri’nin özdeyişleri için de geçerlidir. 


\subsection{Süryani metinlerinde atasözü niteliği taşıyan bazı sözler}

Bilgelik/hikmet merkezindeki erdemli yaşam ve bununla ilgili özdeyişler, Kutsal Kitap'ta olduğu gibi Süryani Büyükleri'nin eserlerinde de geniş bir yere sahiptir. Kullanılan bazı atasözlerinin kaynağı buradaki özdeyişlerdir. Bununla ilgili olarak aşağıda “Ahikar'ın Öğütleri” (Çiçek, 2004) ve Süryani Büyükleri'nden olan Mor Efrem’in (2012) şiirlerinden çeşitli örneklere yer verilmektedir.

\section{a. Doğrudan bilgelik ile ilgili olan bazı sözler}

"Hikmet, silahtan; ilim de maldan daha iyidir." (Mor Efrem, 2012: 394).

“İlim, ikinci bir 1şıktır.” (Mor Efrem, 2012: 394).

"Yüreğinin kör olmasındansa gözlerinin kör olması daha iyidir.” (Çiçek, 2004: 28).

“Sağlıklı ilim elde et ki, bu âlemde rahat yaşayabilesin." (Mor Efrem, 2012: 46).

\section{b. Terbiye/eğitim, doğruluk ve iyilik ile ilgili bazı sözler}

"Çocuğa verilen ceza; bahçeye atılan gübre, hayvana takılan tasma ve merkebin ayağına bağlanan ip gibi faydalıdır.” (Çiçek, 2004: 25).

“Kulaklarından duymayana ensesinden duyururlar." (Çiçek, 2004: 51).

“Cahil olana sopa dahi fayda etmez." (Çiçek, 2004: 27).

“Su havada durduğu an, ... cahil de akıllanır.” (Çiçek, 2004: 30).

\section{c. Yakınlık, dostluk ve yardımlaşma ile ilgili bazı sözler}

"Yakın olan dost, uzak olan kardeşten iyidir." (Çiçek, 2004: 28).

“Hem yakın ve hem de uzak olanlar, senin için dua ederler." (Mor Efrem, 2012: 395).

“İnsanın ihtişamı, karısı ve çocuklarıdır.” (Çiçek, 2004: 26).

“Ağı değiştirdiğin an dostunu kaybedersin.” (Çiçek, 2004: 29).

\section{d. Çalışmak ve geçimini sağlamak ile ilgili bazı sözler}

“Oturmayı sevenin çalışkan olması mümkün değildir.” (Mor Efrem, 2012: 392).

"Bağırılarak ev inşa edilebilseydi, eşek bir günde iki ev inşa ederdi." (Çiçek, 2004: 24).

“Seni ümidinden saptıracaksa, sevdiğin ayağı kes.” (Mor Efrem, 2012: 55).

\section{e. Ekonomik kazanç/tutum ile ilgili bazı sözler}

“Altın, sıkıntıları çoğaltır; ilim ise rahatlık ve hoşnutluk kazandırır." (Mor Efrem, 2012: 392).

“Oğluna açlık ve susuzluğu öğret ki, evini alıştığı gibi idare etsin.” (Çiçek, 2004: 28).

“İnsanın gözü su pınarına benzer; toprakla dolmayıncaya kadar doymaz.” (Çiçek, 2004: 30).

"Ne altın ne de gümüş kazan, çünkü onlarda yas ve sıkıntı mevcuttur." (Mor Efrem, 2012: 46). 


\section{f. Tedbirli/temkinli olmak ile ilgili bazı sözler}

“Coşmuş nehre karşı durmaya çalışma.” (Çiçek, 2004: 30).

"İyilik yapan iyilik bulur, arkadaşına çukur kazan o çukuru boyuyla doldurur." (Çiçek, 2004: 57).

"Eğer bir denemeye girersen, oğluna güvenme" / "Rabb'ine dua et, çünkü kurtuluşun onun elindedir." (Mor Efrem, 2012: 47).

“Kör adamın yoluna taş koyma.” / "Yoksa seni lanetler.” (Mor Efrem, 2012: 47).

“Kavga eden mekânda durma.” / “Çünkü dövüşün sonu ölümdür.” (Çiçek, 2004: 29).

“Silahsız yola çıkma.” / “Çünkü düşmanınla ne zaman karşılaşacağını bilemezsin.”(Çiçek, 2004: 26).

“Gençliğinde doğru hüküm ver ki, ihtiyarlığında saygı göresin.” (Çiçek, 2004: 27).

\section{g. Sıkıntılı hallere dair bazı sözler}

“Sahibini bırakıp senin ardından gelen köpeği taşla.” (Çiçek, 2004: 27).

"Yolları çok olan sürü, kurtların payı olur.” (Çiçek, 2004: 27).

“Sadece kendini yönetme, yoksa seni yönetenler çoğalır.” (Mor Efrem, 2012: 47).

“Zorla kaçırılan biri, kralın hükmüne sığınır.” (Mor Efrem, 2012: 62).

Süryani Büyükleri'nin özdeyişlerinden derlenen bu örneklerde; aklın önemi, ahlaklı olmak, çocuk terbiyesinin ehemmiyeti, yoksula eziyet etmemek, tedbirli olmak, çalışkanlık ve geçimini sağlayabilmek gibi ana temalarla erdemli/bilgece bir yaşam öğütlenmektedir. Bu açıdan özdeyişler, Kutsal Kitap ile paralellik gösterirler. Bu kaynakların dışında, fakat bilgelik ana teması çerçevesinde yukarıda zikredilen sözlerin türevi niteliğinde görülebilecek Süryani atasözleri de mevcuttur:

“İki tanrıya secde edilmez.” (Akçay, 2005: 26; K. 1; K. 3; K. 4; K. 5; K. 6; K. 7; K. 9).

“Akıl altın taç gibidir, herkeste bulunmaz.”(K. 13).

“İnsan, ismiyle iyi olmaz.” (Akçay, 2005: 26; K. 1; K. 3; K. 4; K. 5; K. 6; K. 7; K. 9).

“İyi adam, ağzının meyvesinden doyar.” (K.10).

“Güzel söz, ağızla söylenir” (K. 13; K. 15).

“Akı1, yaşlı ya da genç olmaya bağlı değildir.” (Afram, 2010: 45).

"Küçük yaşta kazanılan ilim, taştaki nakış gibidir" (K. 13).

“Çocukların terbiyesinde babalar, Allah'ın vekilleridir.” (Dolabani, 2004: 56).

“(Tanrı nasıl ailenin Rabbi ise) Baba, -Tanrıdan sonra- ailenin Rabbidir.” (K. 11).

“Düşen -çürük- duvarın altından uzak dur." (Akçay, 2005: 17; K. 1; K. 3; K. 4; K. 5; K. 6; K. 7; K. 9).

“Ekmek ve soğanla geçinenler, Tanrı yolunda daha sadıktır.” (Akçay, 2005: 18; K. 5; K. 9).

Bu örneklerden anlaşılmaktadır ki Kutsal Kitap’ta ve Süryani Büyükleri'nde söz konusu edilen ögütler, Süryanilerin gündelik yaşamlarında karş1lık görerek hem Süryani atasözlerinin 
oluşmasına hem de benzer mahiyete sahip atasözlerinin üretilmesine kaynaklık etmektedir. Aşağıda yer alan atasözleri ise daha çok sosyo-kültürel etkileşimlerden kaynaklanmakta, aynı zamanda yerel öğeleri ve okuma biçimlerini taşımaktadır.

\section{Süryani atasözleri: Sosyal yaşamın iç dinamiklerce yorumunu barındıran ve bunu aktaran atasözleri}

Bilgelik/hikmet ana temasına kıyasla bağımsız denilebilecek Süryani atasözleri için açıklayıcı birkaç örnek verilebilir. Mesela; "Muhalefet, inşa ettirir.” (K. 2; K. 11), "Bozulmazsa düzelmez." (Afram, 2004: 47), "Yı1kılmayan imar edilemez.” (K. 13; K. 14; K. 15) şeklindeki kalıp ifadeler, Süryani cemaati içerisinde birçok iş ve işlemler sırasında kullanılır. "Kargaşaya sebep olmamak" veya "kargaşadan uzak durmak" (Özd. 16/10-14;20/2-3;24/21;25/5-7; 28/2) gibi kutsal öğütlere nispeten bunların bağımsız bir dinamiğe işaret ettiği söylenebilir. Süryani cemaatinin dış gruplar karşısında ve genel politik refleksler açısından uzlaşı yöntemlerinden yana oldukları, diğer gruplarca ortak kabul gören bir nitelemedir. Dolayısıyla bu atasözlerinin belirtilen kabulle çeliştiği düşünülebilir. Süryanilerin grup içi dinamikleri açısından ise bu sözler, pratik girişimlere ve uzlaşımlara aracılık ederler: "Muhalefet, inşa ettirir” sözü, grup içinde hem muhalif girişimlere kapı aralamakta hem de muhalefetin olumlu maksadını ortaya koymaktadır. Tıpkı; ev, inşaat, bağ işleri ile ilgili faaliyetlerde girişimde bulunmak ve işin sağlam bir zemin üzerinden inşa edilmesi gerektiğini ortaya koymak için sıklıkla kullanılan "bozulmazsa düzelmez”, “yıkılmayan imar edilemez” sözlerinde olduğu gibi bir yaklaşım hâkimdir.

Kargaşadan/fitneden uzak durmak, dışarıya dönük uyumlu, aynı zamanda tedbirli davranmak ile ilgili olarak "Körlerin memleketine gidersen bir gözünü kör et.” (K. 11) atasözü örnek verilebilir. Beklenilenin aksine bir tutum sergilenecekse yer yer kullanılan "her fellah, İşo değildir” (K.1; K. 3; K. 4; K. 5; K. 6; K. 7; K. 9) sözü de örnek verilebilir (6). Bu söz, kargaşadan geri durmak yönündeki ögütlerin aksine direnişin ortaya konduğu durumlarda dile getirilir. Bunlar gibi sosyo-kültürel yaşam dinamiklerine işaret eden birçok atasözü mevcuttur. Aşağıda yer alanların bir kısmı (mesela, bilgelik ve terbiye ile ilgili olanlar), yine erdemli bir yaşamı öğütlemektedir, fakat yerelliği yansıtması bakımından farklıdır. Büyük bir kısmı ise nispeten bağımsız bir mahiyete sahiptir.

\section{a. Doğrudan bilgelik ile ilgili olan atasözleri}

“Bin'in başı, -bir- kelimedir.” Bu söz, bir kelime söylemenin ya da ima etmenin, durumun anlaşılması için yeterli olduğunu, konuşmada az ve öz olmak gerektiğini, vurgulamak için kullanılır (K. 13; K. 15).

“İki gün birbirine benzemez.” (Akçay, 2005: 25; K. 1; K. 3; K. 4; K. 5; K. 6; K. 7; K. 9).

“Cahilin yükü her zaman ağırdır.” (Afram, 2010: 45; K. 13).

\section{b. Terbiye/eğitim, doğruluk ve iyilik ile ilgili atasözleri}

"Ya salih bir evlat ya da akarsu." (K.11). Burada akarsu, özellikle bağ-bahçe işleri göz 
önüne alındığgnda, mülk edinebilmenin temel kaynağı niteliğindedir. Salih bir evlat sahibi olmak da bu değerde önemlidir.

"Çocuğun terbiyesi, okuldan daha iyidir." Bu atasözü, aile (anne-baba) terbiyesinin önemini ve önceliğini, ayrıca bu terbiyenin dış kurumlara havale edilmemesi gerektiğini vurgulamak için kullanılmaktadır (K. 5; K. 9). Bu söz, geçmiş yaşam koşullarında Süryanilerin eğitim kurumlarına olan mesafelerinin bir nevi iç karşılığı olarak da değerlendirilebilir.

"Çocuğuna tokat atan, yedi kilise inşa etmiş gibidir." Çocukların terbiye edilmesine yönelik olarak bu söz, geçmişte sıklıkla kullanılırdı (K.1; K. 3; K. 4; K. 5; K. 6; K. 7; K. 9).

"Ne utanan adamdan ne de çok gülen kadından bir şey beklenmez." (Akçay, 2005: 36; K. 1; K. 3; K. 4; K. 5; K. 6; K. 7; K. 9).

"Buğdaylar arasındaki zizonê gibi oldu."(Afram, 2010:43). Süryanicede "zizonô"(çoğulu: zizonê) terimi buğdaylar arasındaki zararlı ota denilmektedir. Bu söz, aile terbiyesine yakışmayan davranış sahiplerinin durumunu eleştirmek için kullanılmaktadır (K.2).

“Katırlarla birlikte arpa yer.” (Afram, 2010: 42). "Katırlarla beraber arpa yeme!” Bu söz, büyüklerin ya da ehil olanların yanında, haddini bilmeyenlerin durumunu belirtmek ve uyarıda bulunmak için sıklıkla kullanılmaktadır (K. 13; K. 14; K. 15).

"Sütünün sağılmasına izin verip, sonrasında süt kovasını tekmeleyerek döken ineğe benzedi." / "Fazla süt verip de daha sonra sütün kovasını deviren inekten ne fayda var." (Afram, 2010: 44). Bu söz, yapılan işe sadık kalınmasını, iyiliği başa kakmamak gerektiğini vurgulamak ve aksi davrananların durumunu belirtmek için kullanılmaktadır (K. 13).

Bu kategorideki atasözleri bilgece öğütleri içermekle birlikte, hayvancılık ve tarım gibi yerel öğeler taşımakta, gündelik yaşam pratikleri üzerinden de örnekler sunmaktadır.

\section{c. Yakınlık, dostluk ve yardımlaşma ile ilgili atasözleri}

“Kardeş kanı, asla su olmaz.” (Akçay, 2005: 29). Bu söz, küs olan kardeşleri barıştırmak, kardeşlerin birbirine küs/düşman olamayacağını vurgulamak için kullanılmaktadır (K. 1; K. 3 ; K. 4; K. 5; K. 6; K. 7; K. 9).

“Evden olmayan, ev halinden anlamaz.” (K. 1; K. 3; K. 4; K. 5; K. 6; K. 7; K. 9).

"Çocuğumun çocuğu, çocuğumdan daha tatlıdır." Torun sevgisini belirtmek için kullanılan bir sözdür (K. 13; K. 15).

"Geldiği yeri bilmeseydik, onu kral zannederdik.”/ "Anne-babanızı bilmeseydik, sizi sultanlar getirdi, derdik.” (K. 10).

“Düşen yük, yerde kalmaz.” (Akçay, 2005: 17). Bu söz, zor durumdaki birine, diğerlerinin yardım edeceğini vurgulamak için kullanılmaktadır (K. 5; K. 9).

$\mathrm{Bu}$ kategori içerisindeki sözler de yerel öğeler taşımakla birlikte, gündelik yaşam hassasiyetlerini ortaya koymaktadır. Ek olarak; Süryanilerde ev-akraba bağlılığının çevre etnik yapılarda olduğu gibi aşiret veya geniş akrabalık etrafinda değil, daha çok anne-baba merkezinde önem kazandığını belirtmek gerekir. 


\section{d. Çalışmak ve geçimini sağlamak ile ilgili atasözleri}

"Köpek gibi çalış, aslan gibi ye.” Çalışıp geçimini sağlamanın teşvik edilmesi için bu söz, sıklıkla kullanılmaktadır (K. 1; K. 3; K. 4; K. 5; K. 6; K. 7; K. 9; K. 11; K. 12; K. 13).

"Borç verilen somun ekmeği gibi bize geri döndü." (Afram, 2010: 42). Geleneksel yaşam koşullarında komşudan ödünç alınan bir ekmeğin tez vakitte iadesi makbul karşılanmaktadır. $\mathrm{Bu}$ söz de borcun çabuk iade edilmiş olmasını ya da iyiliğin bir anda karşılık görmesi durumunu belirtmek için kullanılmaktadır (K. 2).

Dini referanslar, çalışmayı ve başkasına muhtaç olmamayı teşvik etmektedir. Nitekim çevre gruplarca da Süryaniler, görece çalışkanlıklarıyla bilinmektedir.

\section{e. Ekonomik kazanç/tutum ile ilgili atasözleri}

“Ticarette ya yemin edilir ya da yalan söylenir" (Akçay, 2005: 42; K. 1; K. 3; K. 4; K. 5; K. 6; K. 7; K. 9). Yaşam koşullarının zorluğunu ima eden bu sözün Kutsal Kitap’taki bilgelik öğütlerine ters düştüğünü belirtmek gerekir.

“Oğlan dolu ev, altın madenidir.” (Akçay, 2005: 37). Günümüzde kullanımı azalan bu söz, erkek çocuklarına sahip olmanın maddi kazancı ziyadeleştiren bir unsur olduğunu ve erkek çocuğun önemini belirtmek için kullanılmaktadır (K.1; K. 3; K. 4; K. 5; K. 6; K. 7; K. 9). Bir öncekinde olduğu gibi bu atasözünün de bilgece öğütlerin aksini ima ettiği söylenebilir.

“Bıtırlık kimseye kalmaz, tarladaki öküze bile.” (Afram, 2010: 42). Bu söz, maddi refah ile kibirlenenleri, hiçbir şeyi beğenmeyenleri eleştirmek için kullanılmaktadır (K. 2; K. 13).

"Serveti ne iyi olana ne de kötü olana bırak." (K.1; K. 3; K. 4; K. 5; K. 6; K. 7; K. 9). $\mathrm{Bu}$ söz, serveti miras bırakmanın gereksizliğini vurgulamak için kullanılmaktadır. Çünkü iyi olan varis, geçim yönünden kendine sahip çıkabilir; kötü olan ise bırakılacak olan mirası heba eder (K. 1).

"Buğday ekmeği, demir mide gerektirir." (Afram, 2010: 42). Geçmiş yaşam koşullarında buğday ekmeğiyle öğün yemek, maddi refahın bir göstergesi niteliğindeydi. Bu söz de yapılan bir işin zorluğunu, zor olan bu işin de "herkesin harcı olmadığını" vurgulamak içindir (K. 2).

Süryanilerin temel geçim kaynağı; tarım, hayvancılık, zanaat ve ticarettir. Bu kategoride olduğu gibi birçok atasözünde bunlara dair öğeler söz konusudur.

\section{f. Tedbirli/temkinli olmak ile ilgili atasözleri}

“Önce atı kabul edelim, sonra ahırı hazırlayalım.” (Afram, 2010: 44). Bir misafiri kabul etmek ve ağırlamak için, ayrıca herhangi bir işe gerektiğinden çok önce hazırlık yapmamak gerektiğini vurgulamak için bu söz kullanılmaktadır (K. 2).

"Yazın taşını, kışın samanlığa ayırın; ihtiyaç olur." Bol miktarda olan bir şey, yoklukta lazım olur, dolayısıyla tedbir alınması gerekir, anlamında kullanılan bir sözdür (K. 11; K. 13).

“Ağaların bahtına güven olmaz.” (Akçay, 2005: 7; K. 5; K. 9). Bu söz, geçmişte yaygın olan ağalık kurumu ile ilgili ilişkilere dair ipuçlarını ve öğeleri yansıtmaktadır.

“Eşek -bile- düştüğü yeri unutmaz.” (Akçay, 2005: 19; K. 5; K. 9). 
"Elini deliklere sokan kişi 1sırılır." (Afram, 2010: 44; K.2; K.13).

“Korkakları zorlama ki, onlardan yiğit çıkmasın.” (Akçay, 2005: 32; K. 1; K. 3; K. 4; K. 5; K. 6; K.7; K. 9).

Son sözde görüldüğü gibi sosyal hayatta tedbirli davranmak, stratejik konumlanmaları da gerektirmektedir. Tedbirli olmak, bilgelik yönünde olabildiği gibi (cahillerle dost olmamak gibi) sosyal ilişkilerde kendini emniyete almak ile de ön plana çıkan bir özelliktir ve bu özellik, grup içi ilişkilerde de kendini gösterir.

\section{g. Sıkıntılı hallere dair atasözleri}

"Boğulmakta olan biri, elini samana bile uzatır." (Afram, 2010: 43). Olmadık seçeneklere başvurma çaresizliğini belirtmek için kullanılan bir sözdür (K. 2).

“Çok yükseğe baktık, başımız alçak yere geldi.” (Afram, 2020: 46; K. 2).

"Her yokuşun ardında bir iniş vardır." (Afram, 2020: 46; K. 2).

“İnsan kendi eliyle evini yıkar.” (Akçay, 2005: 27; K. 1; K. 3; K. 4; K. 5; K. 6; K.7; K. 9).

“Ağrımayan başa eşarp gerekmez.” (Lethin, 1972: 92; Akçay, 2005: 7). Bu söz, yersiz müdahalelerden ve sorunlardan uzak durulması gerektiğini belirtmek için kullanılmaktadır (K. 5; K. 9).

"Sen nerede, Botélilerin (Bardakçı köyü) bayramı nerede." (Akçay, 2005: 39). Bu söz, birinin bir işi başaramadığı veya o işte geç kaldığı zamanlarda kullanılır (K. 1; K. 3; K. 4; K. 5; K. 6; K.7; K. 9). Bu atasözünün çıkış kaynağıyla ilgili anlatılan bir hikâye ise şöyledir: Bardakçı köyünün papazı, bir tasa bıraktığı kırk nohut ile büyük orucun günlerini hesaplarmış. Evin gelini, papazın nohut sevdiğini düşünerek tasın içine sürekli nohut ilave edermiş. Bu da hesapların yanlış/geç tutulmasına sebep olurmuş (K. 9).

"Bıçak, kemiğe dayandı.” (Afram, 2010: 45).

"Vaziyet/durum, bozuk tekerleğe benzer." (Afram, 2020: 46).

"Sabanı çekti ve buzağıyı saldı.” (Afram, 2020: 46).

"Kendine bir tane somun ekmek pişirecek tandır bırakmadı." (Afram, 2010: 43). Kendi eliyle seçeneklerini yok etti, kendini perişan hale getirdi anlamında kullanılmaktadır (K. 2).

"Bıçak kemiğe dayanınca bağırılır.” (Akçay, 2005: 11). Biri acıyla sesini yükseltmişse, bıçak kemiğe dayanmıştır, anlamında kullanılan bir sözdür. (K. 5; K. 9). Başka bir ifadeyle, bu söz ile hem sabırlı olmak hem de sabrın taştığı an söz konusu edilmektedir.

"Başını eğen kadının başını, dünya toplansa kaldır(a)maz." (Akçay, 2005: 10). Burada söz konusu olan mesele, kadının üzülmesi veya kahırlanması değildir. Bu söz, misafirlere karşı cömert olmayan bir kadının, yüzünü ekşitme durumunu ifade etmek için kullanılmaktadır (K. 5; K. 9).

“Geçen sene yumurta derdi, bu sene çörek (kake) der.” (Akçay, 2005: 20). Geçmiş yaşam koşulları açısından yumurta tüketimi, refahın göstergelerinden sayılırdı. Bu söz de iyiye giden işlerin veya iyi olan kişinin kötüleşmesi durumunda kullanılmaktadır (K.1; K. 3; K. 4; K. 5; K. 6; K. 7; K. 8; K. 9). 
"Yılan tarafindan 1sırılan, halatın sallanmasından korkar." (Lethin, 1972: 99; Afram, 2010: 44). Burada korku sendromu betimlenmektedir. Korku sendromunda olan birinin durumunu belirtmek için bu söz kullanılmaktadır (K. 2).

"Yükseldi, yükseldi, sonunda zibil yığınına düştü.” Bu söz, kibrinden veya hadsiz hedeflerinden dolayı kendini yücelten, sonra da umduğu hedeflere ulaşamayan kişinin durumu için kullanılmaktadır (K. 3; K. 15).

"Her çekiç vuran, demirci olamaz." (K. 13).

"Yüksek dağlar, bulutları -tehlikeleri- üzerine çeker." (Afram, 2010: 42).

"Deliğe giremeyen tilki (bu yetmezmiş gibi) kuyruğuna dal da bağladı." Bu söz, birinin işlerini kendi eliyle zorlaştırdığını belirtmek için kullanılmaktadır (K. 9).

Bu kategorideki atasözlerinin büyük bir kısmı kırsal ve tarıma dayalı yerleşik yaşamın unsurlarını yansıtmaktadır. Demircilik de dikkat çekmektedir. Nitekim Süryaniler; gümüş, dokuma, demircilik, marangoz vb. zanaatlarda maharetli olarak bilinirler.

\section{h. Meselelere ve çözüm yollarına dair atasözleri}

“(Gelin istemeye) Ya büyük yalanla ya da bolca altınla gidilir.” (K.1; K. 3; K. 4; K. 5; K. 6; K. 7; K. 9). Yerel dinamikleri ve stratejik tedbiri yansıtan bu söz, anlaşıldığı üzere bilgece öğütlere ters düşmektedir.

"Evin papazınabarıkhmor denmez." (Akçay, 2005: 20). Süryanilerde "barıkhmor", “Allah, sizi ve bizi bereketlendirsin, korusun!" temennisiyle kullanılan bir dua ve selamlaşma sözcüğüdür. Bu söz, ehil olmayan bir kimsenin, işi ehline öğretmeye girişmesi durumunda kullanılmaktadır (K. 1; K. 8; K. 9).

“Evin erkeği olmazsa -hiç değilse kapıdaki- desteğe (stuné) danış.” Bu söz, başına buyruk davranmayıp, az da olsa danışılması, iki sefer düşünülmesi gerektiğini belirtmek için kullanılmaktadır (K.9).

“Keçiye bak, sütünü öyle sağ.” Geçim biçimini yansıtan bu söz, özellikle gelin tercihinde, annesinin ahlaki ve zihinsel özelliklerinin de önemli olduğunu belirtmek ya da bir işin yapılıp yapılamayacağını koşullarından hareketle kararlaştırmak gerektiğini vurgulamak için kullanılmaktadır (K. 13).

“Aşçılar çoğaldığı vakit, yemeğin tadı bozulur.” (Afram, 2010: 45). Bu söz, bir işe gereğinden fazla kişinin müdahale etmesi durumunda, neticenin olumsuz olacağını belirtmek ve buna engel olmak için kullanılmaktadır (K. 2).

"Ekmeği yese bile onu pişirmesi için fırıncıya (yani ehline) ver.” (K. 11; K. 13).

"Yeni şarap, eski tuluma konmaz.” Bu söz, somut anlamıyla birlikte, gündemdeki yeni meselelerin çözümü sırasında; daha önce o konuda tecrübeli, fakat yaşlandığı için konuya hâkimiyetini kaybetmiş birine karşı alınacak mesafeyi belirtmek için kullanılmaktadır (K. 13).

“Erkekler ambara giderler, kadınlar imdada giderler." (Akçay, 2005: 19). Düşman tehlikesinin olduğu ya da erkeğin eşini dövdüğü sırada kadının aldığı pozisyonu ifade eden bir sözdür (K. 5; K. 9). 
Bu kategoride yer alan atasözleri de ekseriyetle sosyo-kültürel öğelere ve hassasiyetlere dair ipuçları sunmaktadır.

\section{Bazı durumları betimleyen atasözleri}

"Sürüsüz Koçer olmaz, bağsız da Tur'lu (Turabdinli) olmaz." (Akçay, 2005: 40; K.1; K. 3; K. 4; K. 5; K. 6; K. 7; K. 9). Turabdin bölgesi Süryanilerin ana coğrafyalarından biridir. Yerel ifade (Tur) içeren bu atasözü, Süryanilerin tarım ile olan bağlarını yansitmaktadir.

"Asaleti olmayan kişi, asil olanı abartarak anlatır." (K. 11; K. 13).

"İnek sahipleri eşek sahiplerinden maya almaya gittiler." Bir işi, ilgisiz bir yerde veya maddi açıdan daha düşük birileriyle çözüme kavuşturmanın yanlış olduğunu belirtmek için kullanılmaktadır (K. 13).

“Aslan aslandır, erkek kadın fark etmez.” Bu söz, erkeklerin işleri de dâhil olmak üzere girişken ve çözüm üreten cesaretli kadınlar için kullanılmaktadır (K. 13; K. 15).

“Ören kişi, pamuğu -geri- getirdi.” (Afram, 2010: 44). Birinin bir işi üstlendiği halde o işten vazgeçtiğini ifade etmek için kullanılan bir sözdür (K. 2). Bu söz, dokumacılık unsuru da taşımaktadır.

“Şeytanın eşeğine bindi, şeytanın eşeğinden inmiyor." (Afram, 2020: 47). "İçine şeytan bulaştı." İnatçılık yapan birinin durumu için kullanılan bir sözdür (K. 2).

"Küçük bayram, büyük bayramdan önce geldi." (Akçay, 2005: 34). Bu söz, Nisan ayındaki büyük oruca müteakip Paskalya bayramı ile Aralık ayının 25. Günü olan Yaldo bayramına atfen; küçük kardeşin büyüğünden önce evlenmesi durumunda kullanılmaktadır (K.1; K. 3; K. 4; K. 5; K. 6; K. 7; K. 9).

“Lokma, ağza geldi." (Afram, 2010: 44). Bir kararın çoktan verildiğini ya da bir işte geriye dönüşün ol(a)mayacağını belirtmek için kullanılmaktadır (K. 2).

“Ekmeği kulaklarımızla yemiyoruz.” (Lethin, 1972: 93; Afram, 2010: 43). Bu söz, haksız eleştirilen birinin aptal olmadığını ifade ederken kullanılmaktadır (K. 2).

"Çanın çalması, bulgurun pişirilmesi demektir." Akşam duası için vuran çan, aynı zamanda akşam yemeğinin habercisidir, anlamında kullanılan bir sözdür (K. 11).

“Gönlümüze göre soğan kesti.” (Afram, 2020: 46). Bu söz, her şeyi gönlümüze göre yaptı veya gönlümüzce ağırlandık anlamlarında kullanılmaktadır (K. 2).

“Kiliseden çıktı, şeriatı öğrendi”. Bu söz, bir konu hakkında fikri olmayan birinin, beklenmedik bir durumda etrafındakilere nasihat etmeye başlaması durumunda kullanılmaktadir (K. 15).

Kutsal Kitap’tan ve Süryani Büyükleri’nin özdeyişlerden bağımsız bir şekilde oluşmuş, aynı zamanda Süryanilerin sosyo-kültürel yaşam koşullarını ve etkileşim biçimlerini yansıtan, özgül bakış açılarını içeren Süryani atasözleri; “çan”, "kilise”, “demircilik”, “dokumacılık”, “Tur” (Turabdin), "yumurta”, “çörek” (kake) gibi köklü kültürel öğeleri içermekle birlikte asalet, ticaret, ekonomik tasarruf ve akrabalık ilişkilerine yönelik olarak da aklî, pragmatik ve stratejik denilebilecek okuma biçimlerini barındırmaktadır. $\mathrm{Bu}$ atasözlerinde yerleşik hayat, tarım, hayvancılık, zanaat ve ticaret ile ilgili öğeler yoğunluk kazanmaktadır. 
Bunlardan "a", "b", “c” ve "d" kategorilerinin dişında kalan atasözlerinin nispeten daha bağımsız; "e" ve "h" kategorisinde olduğu gibi de bir kısmının hikmet/bilgelik merkezindeki öğütlere ters düşen anlam içeriklerine sahip oldukları görülmektedir. Bununla birlikte, "a" kategorisinde açıkça görüldügü gibi Kutsal Kitap'in ve özdeyişlerin yoğunlaştığ 1 alanlarda sosyo-kültürel dinamiklerin kaynaklık ettiği atasözlerinde bir azalma dikkat çekmektedir. Bu da ilgili konularla alakalı sözlerin mevcut olmasıyla ve bu sözlerin karşılık görebilmesiyle açıklanabilecek bir durumdur. Diğer konularda ise sosyo-kültürel dinamiklerin belirleyici olduğu ve sayıca bunların küçümsenmeyeceği görülmektedir.

Yapılan saha çalışmasında Ercan Akçay'ın (2005) 444, Gabriyel Afram'ın (2010) 39 adet olarak derlediği atasözlerinin büyük bir kısmının Mardin'de yaşayan Kadim Süryaniler arasında kullanılmadığı veya hatırlanmadığı görülmüştür. Bu da atasözlerinin sosyo-kültürel etkileşimlerdeki kullanım dinamiğinin zayıfladığını göstermektedir.

\section{Sonuç}

Makalede Süryani atasözlerinin üç temel kaynağı olduğu tespit edilmiştir: Birincisi Kutsal Kitap'tır. İkincisi, Kutsal Kitap'ın vurgulamalarıyla şekillenen Süryani Büyükleri’nin özdeyişleridir. Üçüncüsü ise bunlardan bağımsız bir şekilde atasözlerine kaynaklık eden sosyokültürel yaşam dinamiğidir ki buna çevre grupları da dâhildir. Kutsal Kitap 'tan ve özdeyişlerden kaynaklanan atasözlerinin erdemli ve bilgece öğütlerin aktarılmasına aracılık ettiği, dini yaşayış ve hassasiyetler açısından bu nitelikteki sözlerin sosyal yaşamın açıklanması ve yorumlanmasında etkin bir rolü olduğu, bu etkiyi koruduğu ve aktardığı görülmüştür. Üçüncü kategorideki atasözlerinin ise kimisi özdeyişlere ters düşen, kimisi de yerel isim ve nitelikleri imleyen bir içeriğe sahip olduğu ve bunların yerleşik hayat, tarım, hayvancılık, ticaret, zanaat etrafındaki sosyo-kültürel yaşam ve etkileşimlerle belirlendiği, bu dinamikler temelinde oluşan okuma biçiminin aktarılmasında rolü olduğu sonucuna ulaşılmıştır.

Kadim Süryani cemaati hem Kutsal Kitap'taki sözler hem de Süryani Büyükleri'nin özdeyişleri ve kullanılan diğer atasözleri itibariyle sözlü kültür unsurlarını taşımaktadır. Fakat bu unsurlar, günümüz itibariyle zayıflamıştır. Bunun en açık göstergesi, sosyal dinamiklerden kaynaklanan atasözlerinin azalması ile atasözlerinin menşei ile ilgili olarak Kutsal Kitap merkezli yaklaşımların grup içinde güçlü bir şekilde oluşmuş olmasıdır. Bununla birlikte, Kutsal Kitap ve özdeyişlerden kaynaklanan atasözlerinin sosyal yaşamı bilgelik yolunda beslediği, desteklediği, bu minvalde bir yaşamın inşa edilmesine ve aktarılmasına aracılık ettiği görülmüştür.

Kutsal Kitap'ın sunduğu erdemlerin sosyal yaşama aktarılması sürecinde, ilgili öğütlerin atasözü formuna dönüştüğü, aynı dönüşümün Süryani Büyükleri’nin özdeyişleri için de söz konusu olduğu tespit edilmiştir. Bu sözlerin kullanımı sırasında, tabii bir durum olarak sözün kaynağından ziyade sözün etrafinda şekillenen ögütlerin ve davranış formunun önem kazanmasından dolayı bunlar, atasözü formunda rolünü sürdürmüştür. Modernleşme süreci ve nüfusun azalması gibi sebepler, sözlü kültür dinamiklerinin ve neticede atasözü yoluyla kurulan iletişimin zayıflamasını, aynı zamanda modern okuma yoluyla sözlerin kaynağını sorgulamaya dönük bir yönelişi beraberinde getirmiştir. Süreç, sosyal yaşam dinamiğinin soyut düşünsel (ideolojik) alana çekilmesi olarak da yorumlanabilir. 


\section{Notlar}

1 Atasözü; Arapçada "mesel”, “darb-1 mesel”, "emsal”, "hikmet”, "hisse”, Farsçada "pend”, Yunancada "parabol", Latince ve Fransizcada "proverbe" ve İngilizcede ise "proverb" terimleriyle ifade edilmektedir (Kaya, 2007: 110). "Mesel" terimiyle belirtilen atasözünün Sami dillerindeki kullanımı ortaktır: Habeşçede "mesl", "messale"; Aramicede, "masla"; İbranicede "masal” terimleriyle ifade edilmektedir. (Brockelmann, 1979: 120).

2 Makalede "sözlü kültür" terimi, özellikle yüz yüze sözlü iletişimi ve bu iletişimin sosyal bağlamını kastederek kullanılmaktadır (Bk. Ong, 2003: 23-24).

3 Süryani Ortodokslar, 6. yüzyılın sonlarından 19. yüzyıla kadar, zaman zaman Yakubi, zaman zaman Süryani Ortodoks, bazen de Yakubi-Süryani olarak adlandırıldılar. "Kadim” tabiri, Süryani Ortodokslar arasındaki bir bölünme neticesinde Katolik kilisesine bağlananlar karşısında ana yapıyı temsil eden Süryaniler için kullanılmıştır (Günel, 1970: 35; Akyüz, 2005: 222-223). Seyfeli'nin 1835 yılına ait Osmanlı belgesi araştırmalarına göre de Katolik Süryaniler, sadece Süryani ismiyle anılırken Kadim Süryaniler ise "Yakubi Süryaniler" olarak zikredilmektedir (Seyfeli, 2005: 127). Yakubi ismi, Yakup Baraday’a (d.500-ö.575) izafeten kullanılmaktadır. "Süryani Kadim Ortodokslar”, Mor Yakup'u aziz olarak kabul edip saygıyla anarlar. Fakat günümüzde Süryaniler, bu isme; Bizans gruplarının "Süryani Kadim Kilisesi'nin elçisel olmadığını” vurgulamak amacıyla kullanıldığı ve bunun kendilerini küçümseyen bir yakıştırma olduğu düşüncesinden hareketle mesafeli yaklaşmaktadır (Akyüz, 2005: 188-189; Tahincioğlu, 2011: 81-83; Seyfeli, 2017: 5). Günümüzde "Yakubi” ve "Kadim" nitelemesi yerine Süryani ismi daha fazla tercih edilmektedir. "Kadim” sözcügünün makalemizde kullanılması, sınırların belirlenmesi amacıyla tercih edilmiştir. "Cemaat" terimi ise "Kilise" sözcüğünün anlamlarından biridir (Seyfeli, 2015: 44). Makalede "cemaat" terimi hem aynı ruhsal gerçeklik içindeki konumlanmaya hem de mekanik olmayan sosyal bir birlikteliğe vurgu yaptığı için kullanılmaktadır.

4 İlgili kaynak şahıslar, metinde " $\mathrm{K}$ " harfiyle ve soy ismin sıralamasına uygun numaralarla kodlanarak verilmektedir.

5 Ahikar'ın Öğütleri, Süryani edebiyatı açısından Hıristiyanlık öncesine dayanan Aramice yazılmış en eski edebi metinlerden biri olarak kabul edilir. Bunun 17. yüzyıla ait Süryanice versiyonu olan el yazması, 2020 sayılı kayıt numarasıyla Cambridge Üniversitesi'nin kütüphanesinde bulunmaktadır (Goodman, 1961: 270). Çalışmada esas alınan eser de bu el yazmasına dayanan, 1981 yılında, Orta Avrupa Metropoliti Yuliyos Yeşu Çiçek tarafından Süryanice yayınlanan, Yuhanun ve Abgar Gülten'in çevirisiyle de Türkçeye kazandırılan eserdir. Süryanice el yazması nüshasından 1963 yılında yapılan diğer bir Türkçe tercüme de Mardin Metropoliti Hanna Dolabani’ye aittir (Gülten'in ve Dolabani'nin önsözü için bk. Çiçek, 2004: 9-17).

6 "Fellah" (çiftçi, işçi) terimi, Mardin’e bağlı Midyat ilçesinde Kürtlerin Süryaniler için kullandıkları bir ifadedir. Günümüzde Süryaniler, küçümseme ima ettiğini düşündükleri bu ifadenin kendilerine yönelik kullanılmasından hoşnut değiller.

\section{Teşekkür}

Yoğun zamanına rağmen “Ordspråk \& Aforismer” adlı eserdeki Süryanice atasözlerinin tercüme edilmesinde yardımlarını esirgemeyen MAÜ Süryani Dili ve Kültürü Anabilim Dalında görev yapan Öğr. Gör. Mihayel Akyüz’e teşekkür ederim. Saha görüşmelerinde yardımlarını esirgemeyen Midyat Süryani Kiliseleri Papazı İshak Ergün'e, Mardin Kırklar Kilisesi Papazı Gabriyel Akyüz’e, Anıtlı köyü muhtarı Habip Doğan’a ve köy halkına şükranlarımı sunarım.

\section{Kaynaklar}

Afram, G. (2010). Ordspråk \& aforismer/Från hela världen. Stockholm: Författares Bokmaskin.

Akçay, E. (2005). Süryani atasözleri. İstanbul: Aram.

Akyüz, G. (2005). Tüm yönleriyle Süryaniler. Mardin.

Assmann, J. (2001). Kültürel bellek. A.Tekin (Çev.). İstanbul: Ayrıntı.

Brockelmann, C. (1979). Mesel. İslâm ansiklopedisi (Cilt. 8, ss. 120-124). İstanbul: Milli Eğitim. 
Çiçek, Y. Y. (2004). Ahikar'ın öğ̈̈tleri. Y. Gülten - A. Gülten (Çev.). İstanbul: Gerçeğe Doğru.

Dolabani, H. (2004). Özdeyişler. İ. Tanoğlu ve S. Tanoğlu (Haz.), Süryani büyüklerinden inciler içinde (ss. 38-73). Elazı̆̆: Çağ.

Goodman, A. E. (1961). The words of Ahikar. D. W. Thomas (Ed.) Documents from old testament times içinde (ss. 270-275). New York: Harper Torchbooks.

Goody, J. (2017). Mit, ritüel ve söz. D. Sezgi (Çev.). İstanbul: Küre.

Günel, A. (1970). Türk Süryaniler tarihi. Diyarbakır.

Kaya, D. (2007). Ansiklopedik Türk halk edebiyatı terimleri sözlüğü. Ankara: Akçağ.

Kutsal Kitap (Tevrat, Zebur, İncil). (2009). İstanbul: Yeni Yaşam.

Mor Efrem (2012). Kilise ataları tarafindan kutsal ruh'un kavalı olarak adlandırlan Süryani Mor Efrem 'in şiirleri. G. Akyüz (Çev.). Ankara: T.C. Kültür ve Turizm Bakanlığı.

Ong, W. J. (2003). Sözlü ve yazllı kültür. S. P. Banon, (Çev.). 3. bs. İstanbul: Metis.

Sanders, B. (1999). Öküzün A 'sı. Ş. Tahir (Çev.). İstanbul: Ayrıntı.

Seyfeli, C. (2005). İstanbul Ermeni Patrikliği (2. bs.). Ankara: Aziz Andaç.

Seyfeli, C. (2015). Ermeni Kilisesi'nde sakramentler. Konya: Çizgi.

Seyfeli, C. (2017). Süryani katolik patrikliği'nin idaresi ve Osmanlı devlet salnameleri (1847-1918).

Dicle Ilahiyat Dergisi, 19(2), 1-26.

Tahincioğlu, Y. (2011). Tarihleri kültürleri ve inançlarlyla Süryaniler. İstanbul: Butik.

Tanrıverdi, E. (2005). Ana hatlarıyla Süryanî edebiyatının tarihî gelişimi. A. Taşğın, E. Tanrıverdi ve C. Seyfeli (Ed.), Süryaniler ve Süryanilik içinde (Cilt. 4, ss. 13-40). Ankara: Orient.

\section{Elektronik kaynaklar}

Lethin, J. B. (1972). Syriac proverbs from California. Western folklore, 31(2), 87-101. doi:10.2307/1498227 (Erişim: 24 Ocak 2020). https://www.jstor.org/stable/1498227.

\section{Kaynak şahıslar}

K.1: Aktaş, Gabriyel, dt: 1947, Alagöz köyü/Midyat/Mardin.

K.2: Akyüz, Mihayel, dt:1986, Merkez/Mardin.

K.3: Aslan, Zeki, dt: 1975, Anıtl köyü/Midyat/Mardin.

K.4: Ay, Hazni, dt: 1984, Anıtlı köyü/Midyat/Mardin.

K.5: Aydın, Bünyamin, dt: 1984, Anıtlı köyü/Midyat/Mardin.

K.6: Büyük, İsa, dt: 1977, Anttl köyü/Midyat/Mardin.

K.7: Çepe, Bünyamin, dt: 1973, Anıtlı köyü/Midyat/Mardin.

K.8: Doğan, Habip, dt: 1966, Anıtlı köyü/Midyat/Mardin.

K.9: Durmaz, Aziz, dt: 1977, Anıtlı köyü/Midyat/Mardin.

K.10: Gürkan, Barsavmo, dt:1998, Midyat/Mardin.

K.11: Kırılmaz, İliye, dt: 1950, Merkez/Mardin.

K.12: Türker, Yusuf, dt: 1964, Midyat/Mardin.

K.13: Y1ldız, Aziz, dt: 1968, Bülbül köyü/Mardin.

K.14: Yıldız, Ildız Meryem, dt:1930, Bülbül köyü/Mardin.

K.15: Yıldız, Mesut, dt:1970, Bülbül köyü/Mardin. 